\title{
Application and Prospect of Straddle Monorail Transit System in China
}

\author{
Xihe $\mathrm{He}^{1}$
}

Received: 9 December 2014/Revised: 14 February 2015/Accepted: 19 February 2015/Published online: 21 May 2015

(C) The Author(s) 2015. This article is published with open access at Springerlink.com

\begin{abstract}
Straddle monorail, using rubber wheels and precast concrete track beams, is a kind of distinctive urban rail transit system, featured with strong climbing capability, small turning radius, less land occupation, low noise, moderate volume, and low cost. Those unique technical characteristics have played an important role in Chongqing urban rail transit lines. Chongqing provides a typical demonstration project, and straddle monorail transit system will be a favorite urban rail transit system for our other mountain cities, landscape cities, coastal cities, historical and cultural cities, etc. And it has laid a good foundation and favorable conditions for further popularization and application of straddle monorail transit system.
\end{abstract}

Keywords Urban rail transit - Straddle monorail - Project application

\section{Summary}

Among the urban rail transit systems, monorail transit system is a typical and popular system with nearly 50-year safe operation in foreign countries especially in Japan, Southeast Asian countries such as Malaysia, Europe, the USA, Canada, and so on.

Monorail is a moderate volume rail transit system with electric vehicles running on a track beam. According to the

Xihe $\mathrm{He}$

cq-hexihe@163.com

1 Chongqing Rail Transit Design and Research Institute, Chongqing 401122, China

Editor: Gary Barber positional relationship between the vehicle and the track beam, it can be divided into two types of monorail such as straddle monorail and suspend type monorail.

Straddle monorail is a kind of monorail system, in which the vehicles use rubber wheels traveling across on the track/beam. Except the walking wheels, there are guiding wheels and stabilizing wheels on both sides of the bogie, which clamp on both sides of the track beam, to ensure the vehicle safely and smoothly running along the track [1].

Not only is Straddle monorail very suitable for mountain city, coastal city, urban and complex terrain, and road city but also for the urban areas surrounded by a high concentration of buildings as well as suburban areas; at the same time, it is a good choice for a low economic growth and fiscal revenue region to develop urban rail transit.

At present, except for the sightseeing area or domainspecific (such as airports, schools) small monorail line, monorail has been built or under construction in the world as a moderate volume urban rail transit system, in the following countries: Japan, Canada, the USA, Germany, Russia, India, Malaysia, Brazil, and South Korea. In Chongqing, we have successfully operated for about $75 \mathrm{~km}$ lines of straddle monorail. Now straddle monorail transit lines in operation and under construction both at home and abroad have exceeded $600 \mathrm{~km}$.

\section{The Technical Characteristics of Straddle Monorail}

\subsection{Unique Technical Advantages of Straddle Monorail}

Track beam system: track beam system of monorail is a kind of precast reinforced concrete beam (PC beam), 
integrated with some embedded parts, structural parts, power supply, and signal facilities. As a result, it has prominent characteristics of small volume, compact structure, good light transmittance, and good landscape for passengers.

Because the vehicle can travel in a small curve radius, and the track are mostly elevated above road Barrier, so a monorail line, which requires less land use than traditional rail system, can make better use of limited city space, is suitable for city construction and could effectively reduce unneeded urban demolition.

The track structure is simple, and its cost is less than metros. Compared with the traditional metro mode, straddle monorail transit system has the characteristics of low cost and high transport efficiency, with about 1/3-1/2 cost of metro.

Vehicle can travel in line of large slope and small curve radius, bypassing urban buildings, so that straddle monorail system is suitable for mountain city and complex terrain environment with strong environmental adaptability.

Vehicles are walking with air springs, rubber wheels, and electric drive, resulting in low noise, comfortable ride, and less environmental pollution. Generally, its noise is over $10 \mathrm{db}$ lower than metro, so it is a better choice for urban traffic.

Line is elevated over urban area, which makes the passengers fell comfortable with good vision, so it has the dual function of urban transportation and tourism (Table 1).

\subsection{Three Main Technical Characteristics}

Monorail, as a new urban rail transit form, has some unique system technologies. In general, the construction of monorail requires three main technical features including monorail vehicles, monorail PC beam, and monorail track switch.

At first, the basic and the core technology of monorail technology system is the monorail vehicle technology. On the one hand, vehicle technology itself is the core technology of the entire rail transit projects; on the other hand, only when the vehicle technology is determined, can we select match switch, PC beams, and other supporting electromechanical equipment systems. The difference of various monorail vehicle technology is mainly reflected by the structure of bogies which is completely different from the subway [2] (Fig. 1).

The second one is monorail PC beam production process and erection technology. Monorail track beam can be divided into two categories of pre-stressed concrete beams and steel track beam according to its different materials: in general, concrete beams use I-shaped sections, and hollow structural and steel beam uses a box-section structure. In a monorail traffic system, track beam is both bearing beam and guide rail, which has the following characteristics:

(1) Small volume, compact structure, factory production, good light transmission, and good landscape.

(2) Precast track beam uses pre-stressed concrete structure, with higher quality and precision when manufacturing and erecting.

(3) Both sides of the track beam have rigid central catenaries.

(4) Beam bottom or the access is provided with cable tray for traction power supply, communications, and signal

(5) Embedded parts of communication, signal and the traction power supply system for installation and interface are embedded into track beams during precast.

Therefore, the most prominent problem is how to solve the balance and stability during the vehicle traveling. In order to ensure requirements of safety operation, smooth, comfort, except for technical problem of the vehicle itself, we shall also resolve the security and linear problem of rail. Our rail is track beam instead of the ordinary steel rail, which is very different at present, we used to adopt prestressed concrete track beam (referred to PC track beam). However, it is far more difficult to make PC track beam to meet the linear requirements of train while running faster than on steel rail. As a result, our track beam system integrated with many kinds of important functions becomes

Table 1 Metro and straddle monorail comparison

\begin{tabular}{llllll}
\hline & Metro & & \multicolumn{2}{l}{ Straddle monorail } \\
\cline { 2 - 3 } \cline { 5 - 6 } & $\begin{array}{l}\text { Minimum radius of curve } \\
(\mathrm{m})\end{array}$ & $\begin{array}{l}\text { Maximum longitudinal slope } \\
(\%)\end{array}$ & $\begin{array}{l}\text { Minimum radius of curve } \\
(\mathrm{m})\end{array}$ & $\begin{array}{l}\text { Maximum longitudinal } \\
\text { slope }(\%)\end{array}$ \\
\hline $\begin{array}{l}\text { Main line } \\
\text { Parking }\end{array}$ & 250 & 35 & Main line & 100 & 60 \\
line & 110 & 40 & $\begin{array}{l}\text { Parking } \\
\text { line }\end{array}$ & 50 & 60 \\
\hline
\end{tabular}



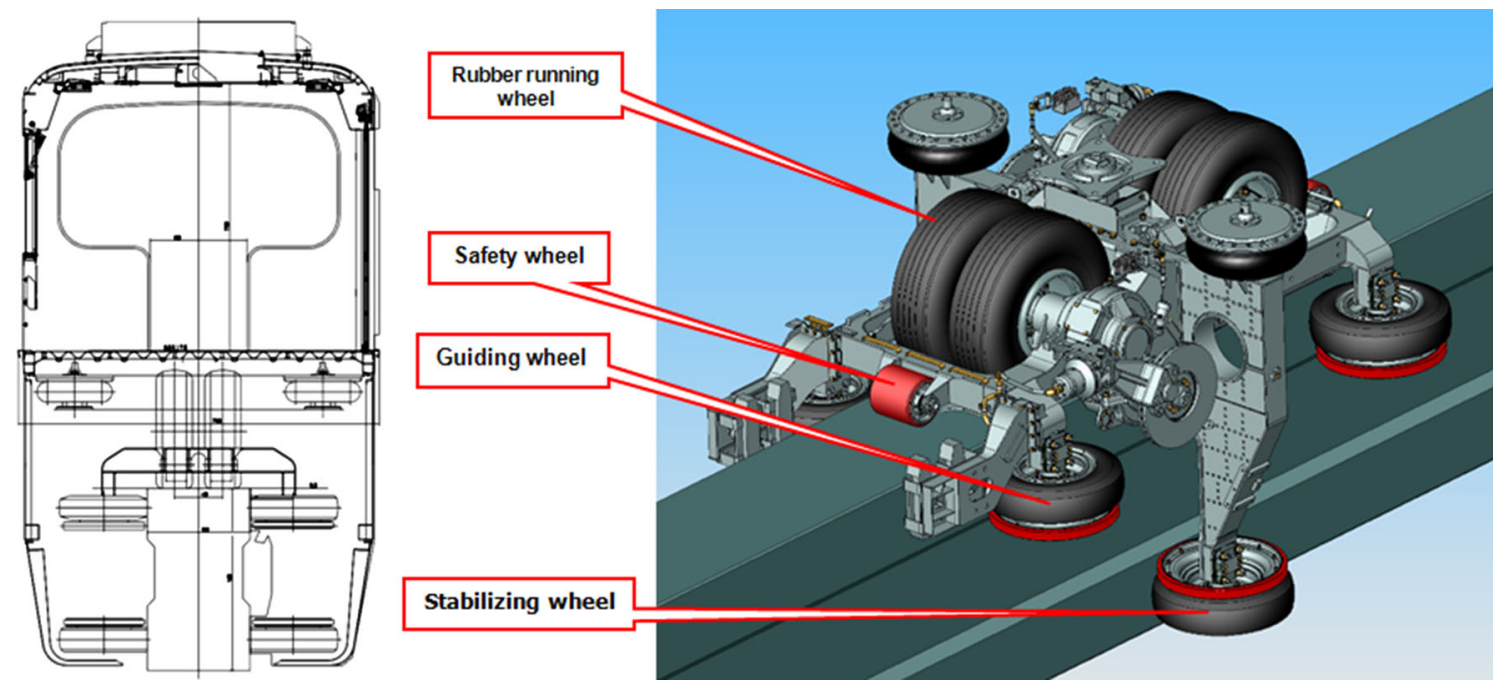

Fig. 1 Typical bogie structure of monorail vehicle

one of the key parts of straddle monorail system. During production and construction, PC track beams are required of not only enough stiffness and strength but also enough surface smoothness. At the same time, the unique erection technology of the track beam is also one of the difficulties (Fig. 2).

$75 \mathrm{~km}$ straddle monorail line in Chongqing line 2 has been completed, and most of them use PC simply supported beam in standard span of $22-24 \mathrm{~m}$, so that the project was implemented with advantages of easy, reasonable cost, convincible line maintenance, etc. For section of crossing interchange, 40-m-span steel rail beam was adopted, as well as some new simple supported beam techniques such as using "simultaneous construction of pier and beam" instead of "beam after pier," the disk rubber bearing beam, $6 \times 30 \mathrm{~m}$ continuous beam, etc (Fig. 3).

After 40 min of 5.12 Wenchuan earthquake in 2008, Chongqing monorail was resumed operations, while the whole track beam system is not damaged (Fig. 4).

Thirdly, straddle monorail system adopts beam type switch, its load, linear, switch, locking, and information feedback which need to meet the requirements for train operation, which is one more key technology to study and solve (Fig. 5).
Monorail switch is a special steel-structure switch in the same section shape with PC track beam. Switch beam is switched to another track beam or another switch beam to realize alignment and to form a fork through electric driving, so that we can help vehicle to change its traveling line. According to the shape of switch beam in transition line (it can be broken line or arc line), monorail switch can be divided into joint switch, joint flexible switch, and flexible switch; according to the number of line alignment, the switch can realize; line switch is divided into single switch, single crossover switch, three switch, and five switch (Fig. 6).

Joint switch and sliding switch are controlled by signal system and switched by drive unit. The structure is greatly different from conventional subway system (Fig. 7).

\section{The Construction of Straddle Monorail in Chongqing}

Chongqing rail transit line no. 2 was constructed as the largest urban infrastructure project after Chongqing became a municipality, which is the first time to introduce monorail transit system in china as an important trial and demonstration project (see Fig. 8).
Fig. 2 Simple track beam structure
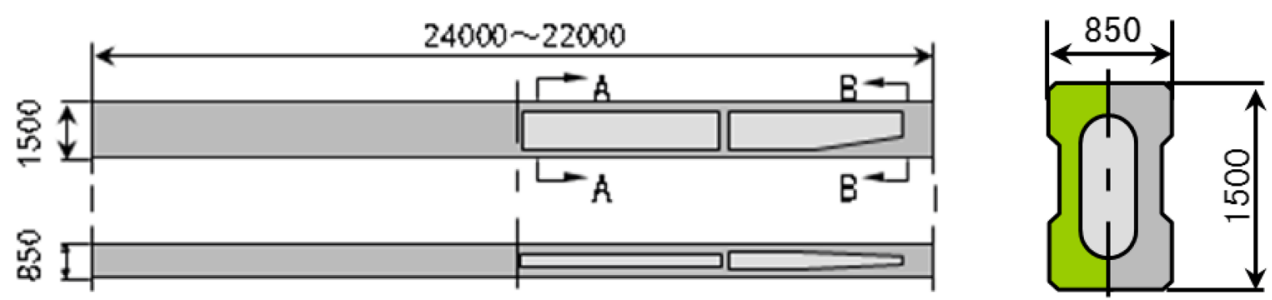
Fig. 3 Continuous steel system of track beam
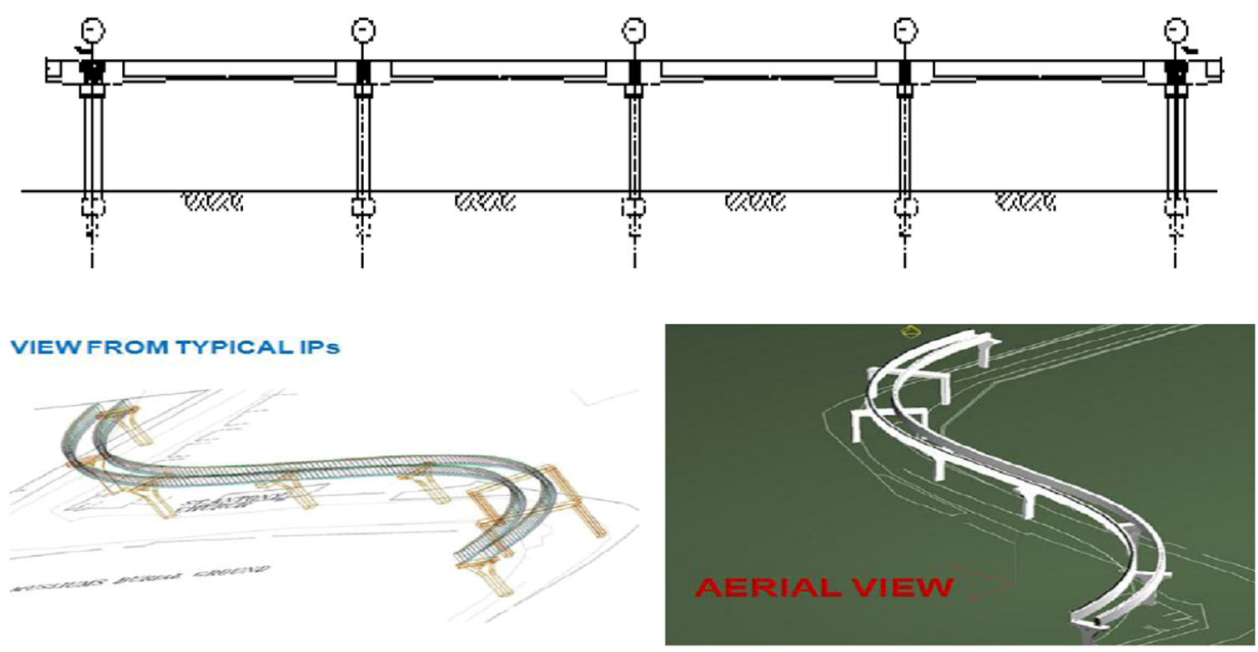

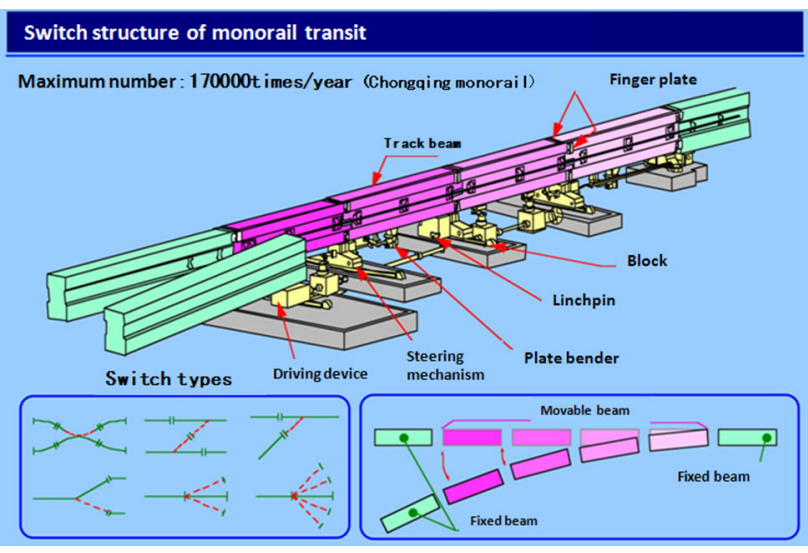

Fig. 4 Joint switch of monorail

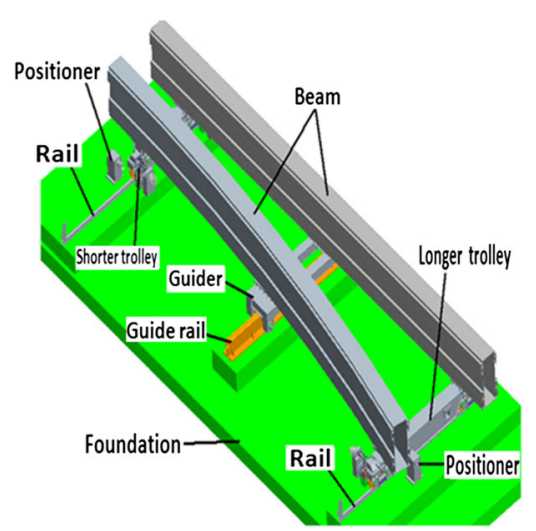

Fig. 5 Monorail translational switch

In 2005 June, with the contemporary international advanced level, as one of the ten key projects of western development, our firstly introduced straddle monorail line - the first phase of Chongqing rail transit line 2 of $14 \mathrm{~km}$ with 14 stations was opened for test operation. After

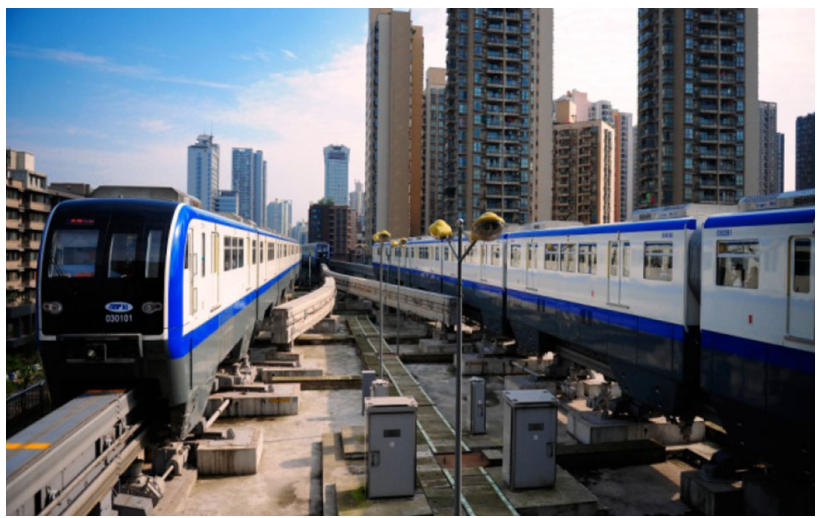

Fig. 6 Switch area of line 3 in Chongqing

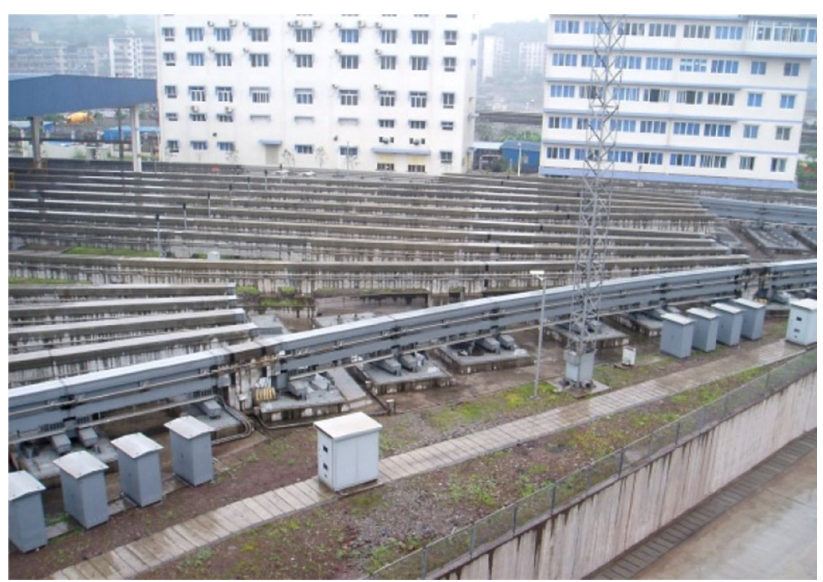

Fig. 7 Switch area of line 2 depot in Chongqing

several years of safe and efficient operation, it showed unparalleled features and benefits than other rail transit systems.

According to the features that line runs through a certain area of high mountains and steep, narrow urban roads, and 


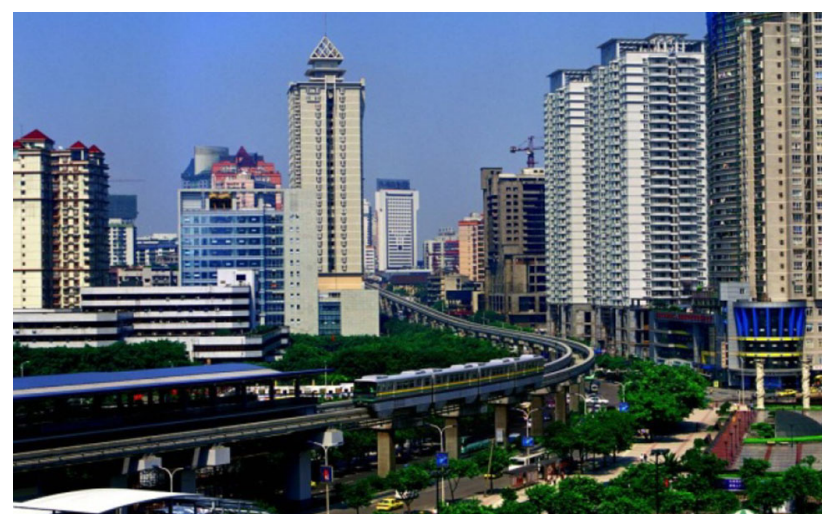

Fig. 8 Through the downtown area of the city

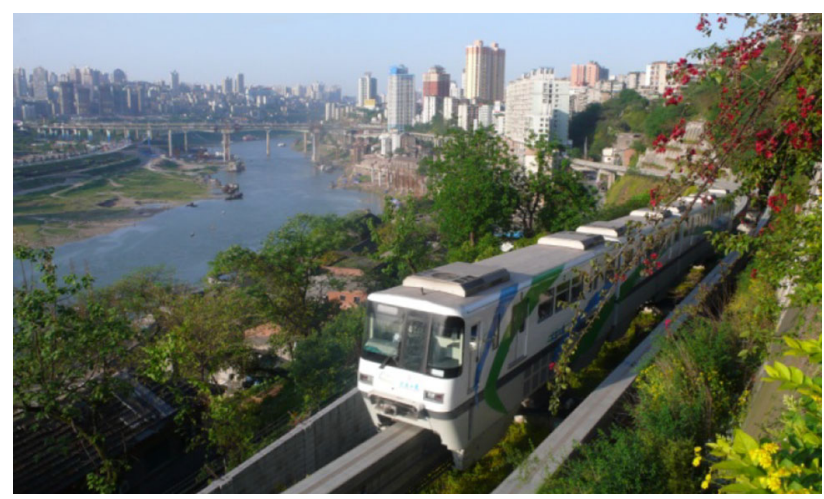

Fig. 9 Along Jialing River

complex terrain, Chongqing rail transit line 2 adopted straddle monorail system and successfully completed and smoothly opened into operation, so as to obviously improve that the residents traveling rate and the quality of urban environment greatly promote the economic development along the route and show a new scene of Chongqing. See Fig. 9.

Chongqing rail transit line three of $65 \mathrm{~km}$ length, among which $56 \mathrm{~km}$ has the trial operation of, 39 stations, 6-car marshalling in initial stage, load capacity of 962 staffs: while in recent and future stage of 8 cars and 1292 passengers; $9 \mathrm{~km}$ north extension section is under construction now. At present, the largest number of passengers in single day is 751,000 people, 700,000 in daily trip, and 2.9 million in peak hour section.

The characteristics of Chongqing straddle monorail: the advantages of straddle monorail system are vividly showed that Chongqing is a city around the world with the biggest scale monorail, the longest monorail line, the largest monorail day volume, which perfectly shows the characteristics of monorail (see Table 2). Monorail line 3 runs through the Yangtze Caiyuanba dual combination of public rail bridge (length: $1866 \mathrm{~m}$, maximum span $420 \mathrm{~m}$ ) and Jialing dedicated monorail bridge (length: $352 \mathrm{~m}$, maximum span $160 \mathrm{~m}$ ). Monorail line 2 sets plum dam station in residential building. See Figs. 10 and 11.

\section{Key Technologies of Straddle Monorail System are Improved and Innovated in Chongqing}

In Chongqing, depending on the construction of straddle monorail transit system in line 2 and line 3, we carry out some localization research upon key technologies, including PC track beam system, switch system, and vehicle bogie system.

\subsection{The Exploration and Innovation of PC Track Beam Production and Construction Technology}

Design and successful application of $24 \mathrm{~m}$ straight PC track beam, which has the same cross-sectional dimensions with $22 \mathrm{~m}$ PC track beam, firstly breaks through the limit condition of PC simply supported beam design conditions of no more than $22 \mathrm{~m}$ span which improves the straddle elevated interval landscape and reduces construction costs. See Figs. 12 and 13.

Furthermore, the main technical difficulties were overcome, such as PC track beam mold localization, construction, measurement and installation of PC track beam, and development of erection machine, so as to reduce the construction investment. See Figs. 14, 15 and 16.

The project won 2008 National Environment friendly Project Award, the Eighth China Zhan Tianyou Civil Engineering Award and science and Technology Innovation Achievements Prize of China, and other national important awards.

As an important measure of the people oriented, Chongqing rail transit line 3 , on the basis of the original line 2, added a maintenance channel in the interval between the two PC track beams overhead. Setting maintenance channel substantially increases in the efficiency of maintenance work and also features both the emergency evacuation of passengers and the role of cable laying. Maintenance channel using transparent steel grid form not only retains the elevated range of good permeability effect but also replaces the cable tray under the track beam (see Fig. 17) [3].

\subsection{Improve the Standard System to Lay the Foundation for Application}

National standard edited mainly by Chongqing Rail Transit (Group) Co, Ltd. "Code for design of straddle monorail transit" (GB 50458-2008), "Code for construction and 
Table 2 Characteristics of Chongqing monorail

\begin{tabular}{ll}
\hline Technical parameters & Main content \\
\hline Topography & City of mountains and rivers, group-style city, road winding down \\
Route & The length of operation line is $75 \mathrm{Km}$ in Chongqing \\
& Line under construction: about $12 \mathrm{~km}$ south extension section of line 2, and $10 \mathrm{~km}$ north extension section of line 3 \\
& The minimum curve radius is $100 \mathrm{~m}$ on main line, while $50 \mathrm{~m}$ in depot \\
& The maximum gradient is $50 \%$ o \\
& Line $2: 4$ and/or 6 cars marshaling \\
Marshaling & Line $3: 6$ and/or 8 cars marshaling \\
& The transportation capacity of 6 cars is up to 1300 \\
Capacity & Peak hour traffic capacity in one-direction section is over 30,000 \\
& Max. capacity/day of line 3 is nearly $1,000,000$ \\
The minimum operating interval can be 2 min in the future; at present, it is 2 min and $40 \mathrm{~s}$ \\
Operation service & $\begin{array}{l}\text { Perfect urban monorail operation services elevated and underground, including air-conditioned waiting rooms on } \\
\text { platforms }\end{array}$ \\
Security & When vehicles or signal system is in trouble, stereo rescue mode and evacuation maintenance channel can be used \\
Shortest construction & Second phase in line 3 is about $19 \mathrm{~km}$; it is planned to be completed in 28 months \\
period &
\end{tabular}

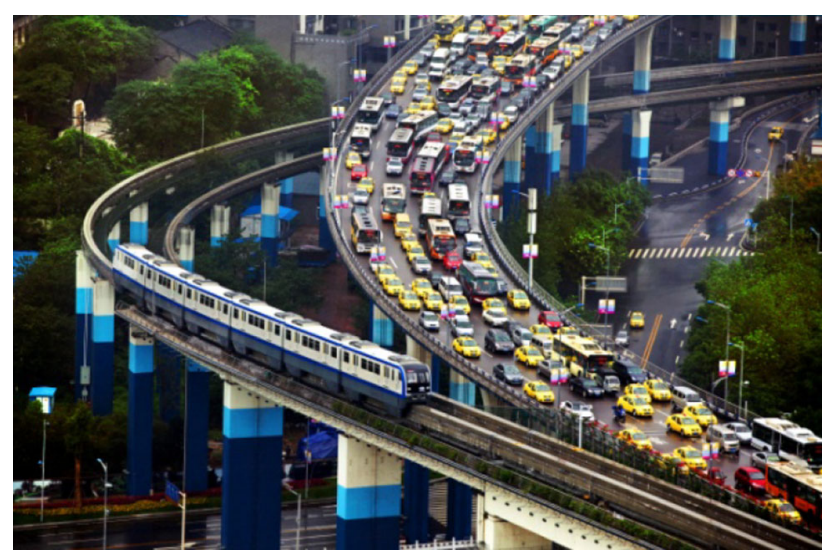

Fig. 10 Across Jialing River Bridge

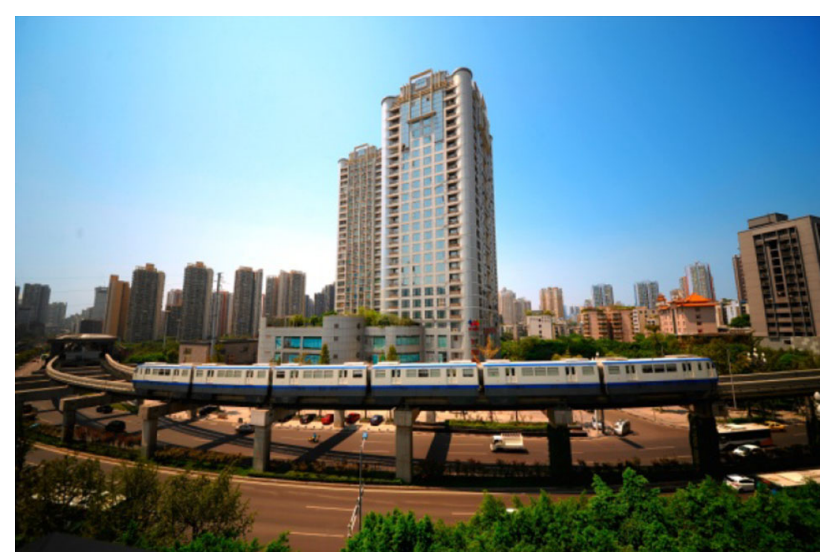

Fig. 11 Through the small curve

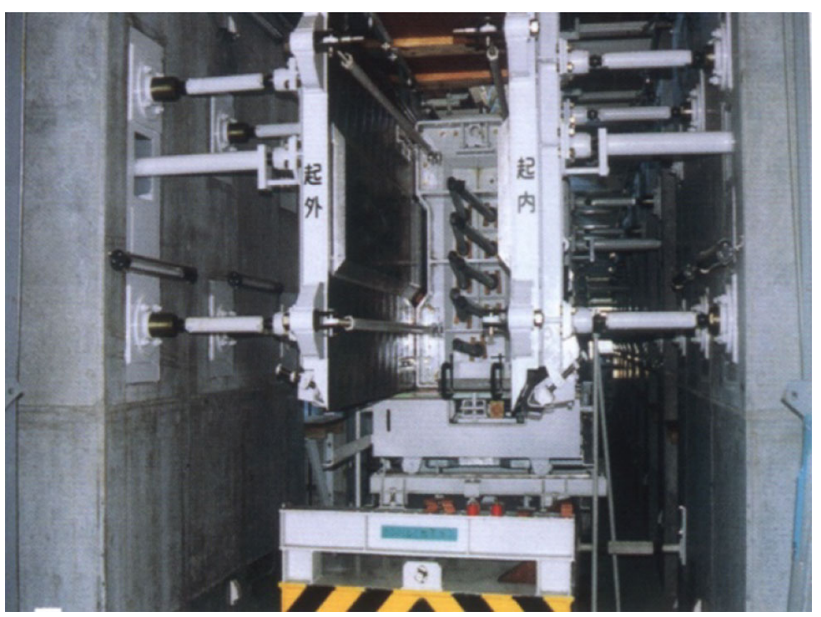

Fig. 12 Fabrication module of track beam

acceptance of straddle monorail transit" (GB 50614-2010), and "General technical specification for straddled monorail vehicle" (CJ/T 287-2008) were respectively formally promulgated and implemented in 2008 and 2009, which filled the gaps between national and industry standards.

Local standards: as the editor in chief, CRT also completed Chongqing local standard "Standard for construction quality acceptance and evaluation of straddle monorail transit," which covers equipment installation and civil engineering of straddle monorail transit system.

Corporate standard: CRT organized and completed some corporate standards with independent intellectual 


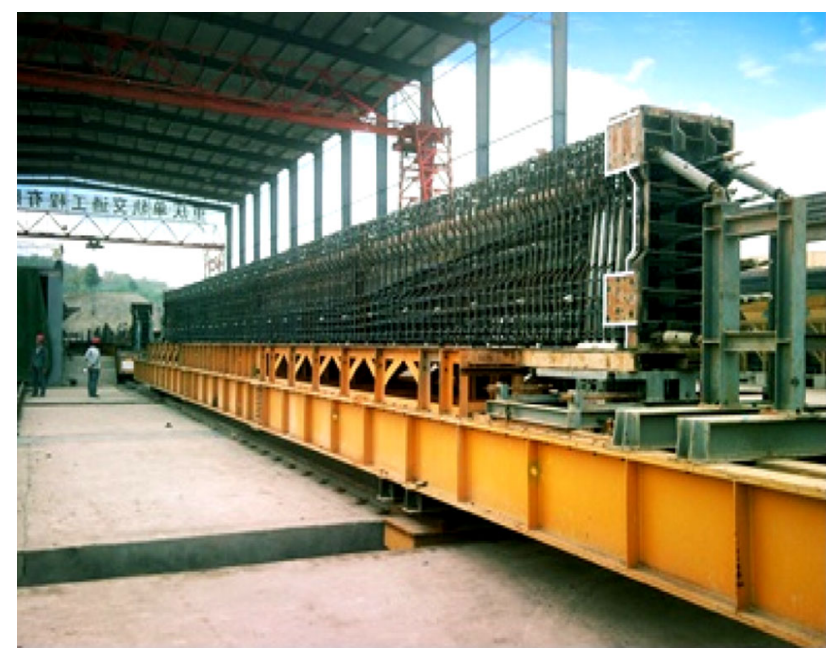

Fig. 13 Factory production of track beam

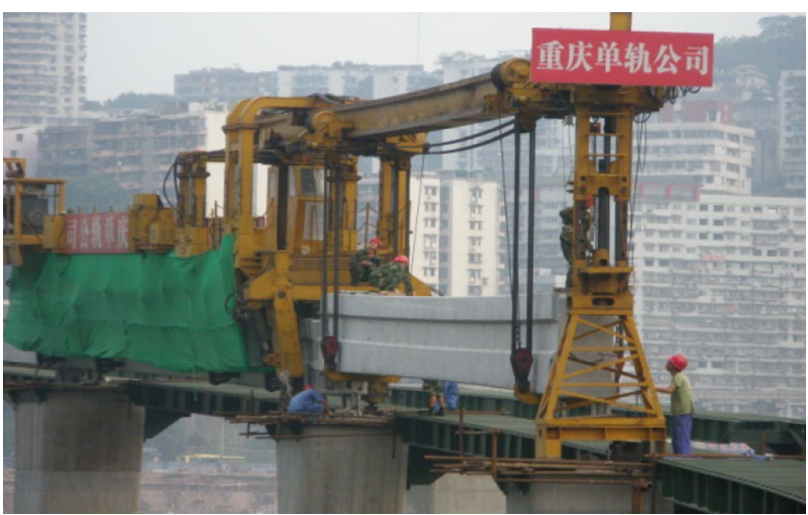

Fig. 14 All terrain, universal PC track beam erecting machine

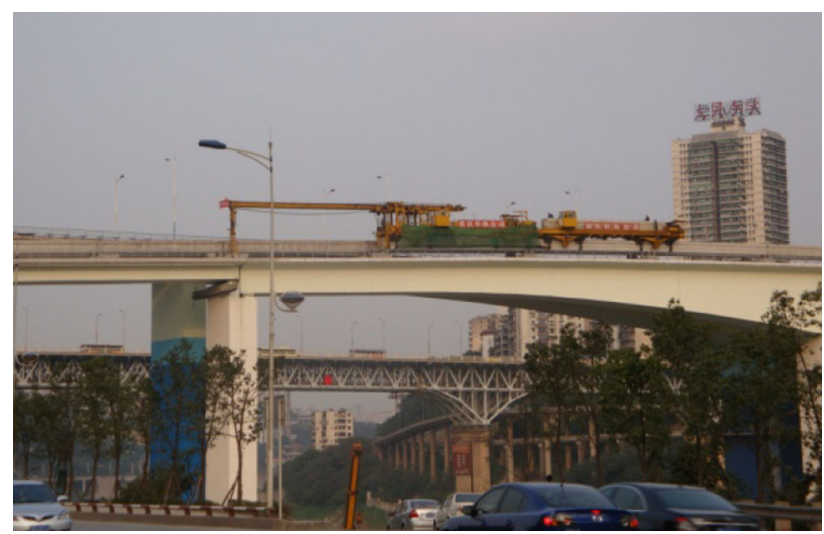

Fig. 15 Beam transport vehicle and erecting machine

property rights, such as "straddle monorail traffic PC track beam finger board manufacturing and acceptance criteria" and "straddle monorail traffic PC track beam steel tension bearing manufacture and acceptance standard."

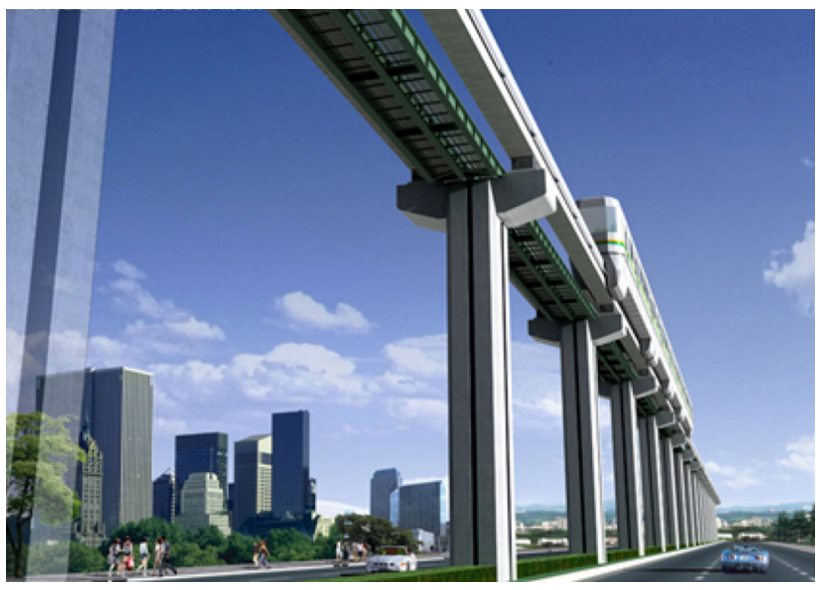

Fig. 16 Maintenance channel in section

Regulations and rules for operation: CRT organized to publish hundreds of regulations and rules for operation, check, maintenance, emergency rescue, and operation management of straddle monorail transit, which forms a perfect management standard system of straddle monorail transit, as well as provides strong guarantee for the safety, efficient operation maintenance, and emergency rescue.

The establishment and improvement of national, local, corporate standards and the standardizing operation system laid a foundation for the further promotion and application of straddle monorail transit system at home and abroad.

\subsection{Technological Innovation Promote Industrial Upgrading}

Based on the ten key projects of western developmentChongqing rail transit line 2, combined with the national and provincial science and technology projects, we completed the straddle monorail transportation equipment system integration, straddle monorail vehicle integration and other key technology R\&D and industrialization technology research, to realize five major and key technology innovations. The research achievements filled the technical gaps in this field of China, totally reached the international advanced level, in which the vehicle traction, disk brake, a new car ATP, sliding switches and other core technology reached the international leading level.

A thorough research on the core technology of key parts and integrated monorail vehicle, switch, train operation control and monorail transit security, system integration and specification standards, made innovative technology system and a number of independent intellectual property rights results.

After the technical innovation for more than 5 years, we completed the whole vehicle integrated design and development, vehicle bogie development, key technology of 


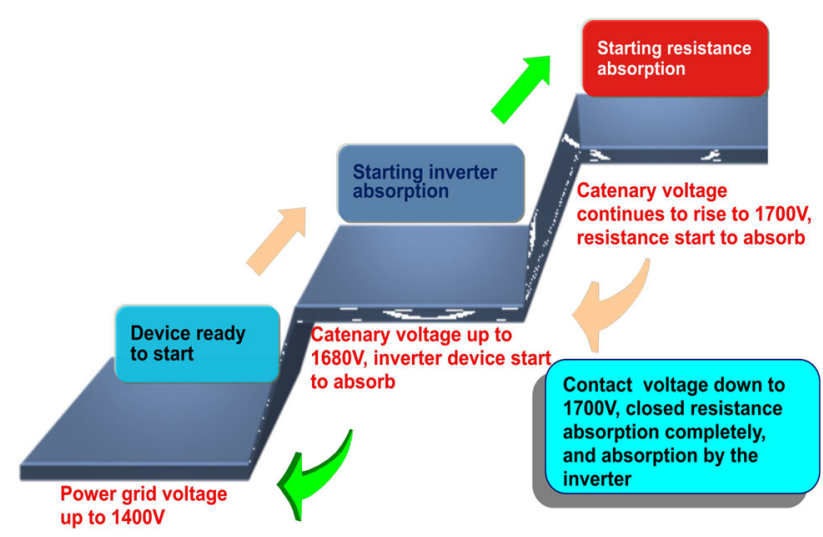

Fig. 17 Inverter absorption device of regeneration energy

vehicle electric traction $R \& D$, vehicle system integration, switch, research, and development of ATP/TD signal system, and development of vehicle mobile real-time video monitoring system, so as to realize the independent development and Industrialization of vehicle and master the core technology of three key components of car body, bogie, and electric traction. Now we have a number of key technologies of straddle monorail switch, automatic overspeed protection and position detection system, mobile real-time video monitoring system, inverter absorption device of regeneration energy (see Fig. 17), security, and emergency rescue, which provides reliable support to technology and equipments, aiming to cultivate and develop straddle monorail equipment emerging industries in china, to popularize straddle monorail technology to the world [4] [5].

Combined with good industrial foundation and strong competitiveness of Chongqing Municipality, relying on the construction of Chongqing Monorail line 2 and line 3 and the R\&D of straddle monorail key technologies, Chongqing straddle monorail equipment manufacturing industry base and a industrial chain came into being after a period of planning and cultivation, a lot of $R \& D$ institutions, academic exchange, and industrial groups were established, such as Chongqing Urban Monorail Engineering Technology Research Center, International Association of Chongqing Monorail, Chongqing Rail Transit Industry Technology Innovation Strategic Alliance and others. By further polymerization of the talent, technology, and manufacturing equipments from enterprises and scientific research institutes, we formed a model of industrial organization featured with external highly specialized division and internal close collaboration, so as to give full play to their core competencies, therefore, we greatly enhanced the Organizational efficiency of urban monorail equipment R\&D and manufacturing resources.

On the other hand, during the promotion and application of straddle monorail system, we need do further research upon safety rescue in elevated section, lightweight of monorail vehicle, and serialization of monorail system, which lead to a more perfect monorail system.

\section{Application and Prospect of Straddle Monorail Transit System}

At present, with Chinese rapid development of small and medium cities urbanization and rapid growth of urban population, increase of urban volumetric rate cars is surged. Due to limited road resources, road congestion is very serious, which seriously affects economic development. To solve the traffic jam, it is necessary to vigorously develop public transport. In a small or medium city with road congestion, we can use tram, monorail, and light rail in a different marshaling best at a high price, an independent right of way to deal with different levels of one-way traffic along the line in order to solve its traffic pressure, while in a city with one-way traffic over 30,000 , we recommend it to choose metro or light rail.

In today's china, both the total operating mileage and the total mileage under construction are more than $2000 \mathrm{~km}$, and the total planning mileage is over $13,000 \mathrm{~km}$. Facing to such scale of Chinese urban rail transit construction, operation, and development, it is an important way to adhere to the principle of "Summary, improvement, innovation," aiming to further improve the city rail transit service quality and promote the city rail traffic health and sustainable development. Therefore, according to urban characteristics (such as mountain city, urban landscapes, coastal cities, historical and cultural city, etc.), how to scientifically select the appropriate urban rail transit system, how to improve its quality and operation service levels through scientific and technological means, how to promote its sustainable and healthy development through technological innovation, will become an important job to play a key role in urban rail transit and to promote its healthy development.

According to preliminary investigation, the global urban rail transit operating mileage of the top ten countries is $19,169 \mathrm{~km}$, of which $12,312 \mathrm{~km}$, or $64 \%$, is light rail and tram, while MTR systems mileages are $6857 \mathrm{~km}$, or $36 \%$. Russian is the No.1 with urban rail traffic operation mileage up to $3853 \mathrm{~km}$, of which $3357 \mathrm{~km}$ is light rail and tram, accounting for $87 \%$, MTR $496 \mathrm{~km}$, accounting for $13 \%$. The second country is German with 3795 total $\mathrm{km}$ of which $2,876 \mathrm{~km}$ is light rail and tram, accounting for $76 \%$ and MTR $919 \mathrm{~km}$, accounting for $24 \%$. Thirdly, America is $2607 \mathrm{~km}$ in total, of which $1391 \mathrm{~km}$ is light rail and tram, accounting for $53 \%$ and MTR $1216 \mathrm{~km}$, accounting for $47 \%$. Fourth is China inland, with the total mileage of $2077 \mathrm{~km}$, of which $338 \mathrm{~km}$ is light rail, tram, and maglev, 
accounting for $16 \%$ and MTR $1740 \mathrm{~km}$, accounting for $84 \%$. Here is no longer enumerating. In short, in the ten most populous countries of urban rail transit, China is the only country to adopt metro system primarily; the rest are light rail and tram. Obviously, it is indeed necessary to optimize the constituent ratio of Chinese urban rail transit systems. Generally speaking, large volume metro is suitable for mega city center area; in suburbs, especially outer suburb district, moderate volume light rail including monorail and low volume modern tram is appropriate. To contact the satellite cities, we use city domain fast track, and light rail and tram are more suitable for the center city. Taken Chongqing as an example, monorail can also be adopted in appropriate number in center city. Mediumsized cities are also advised to use lighter rail vehicles and tram. Such multi-system coordinated development is scientific, economic, and sustainable. Therefore, the demand of straddle monorail transit system with medium capacity, low cost, and short construction cycle will gradually increase. In the future urban rail transit construction, straddle monorail transit system has great room for development in China.

\section{Conclusion}

With the rapid development of small and medium cities urbanization in China and rapid growth of urban population, increases of urban volumetric rate cars are surged at present. Due to limited road resources, road congestion is very serious, which seriously impacts on economic development. To solve the traffic jam, it is necessary to vigorously develop public transport. With the road congestion, we can use tram, or monorail, or light rail in a different marshaling best at a high price, an independent right of way to deal with different levels of one-direction traffic along the line in order to solve its traffic pressure. While in a city with one-way traffic over 30,000 , we advise it to choose metro or light rail.

Straddle monorail traffic system has mature technology with superior technical performance of vehicles. what is more it has significant advantages in operating noise, climbing ability, turning radius, circuit model, and engineering investment; thus, it not only meets with the terrain characteristics of Chongqing, a city with mountains and rivers, but also has very broad promotion and application prospects in other cities of China.

Open Access This article is distributed under the terms of the Creative Commons Attribution 4.0 International License (http:// creativecommons.org/licenses/by/4.0/), which permits unrestricted use, distribution, and reproduction in any medium, provided you give appropriate credit to the original author(s) and the source, provide a link to the Creative Commons license, and indicate if changes were made.

\section{References}

1. GB50458 (2008) Code for design of straddle monorail transit [S]. China building industry press, Beijing

2. CJ/T287 (2008) General technical specification for straddled monorail [S]. Standards Press of China, Beijing

3. Zhong J (2009) Idea of green light rail reflected and developed in Chongqing rail transit [J]. Urban Rapid Rail Transit 22(1):2-6

4. He X (2014) Equipments' developing and industrialization of straddle monorail transit in Chongqing [J]. Urban Rapid Rail Transit 27(2):6-10

5. Lu M, Yang Q, He X et al (2012) Numerical simulation analysis of the translational turnout in the straddle type monorail. China Railw Sci 33(1):13-18 